\title{
VIDEO ANIMASI 2D KESELAMATAN DAN KESEHATAN KERJA PADA LABORATORIUM
}

\author{
Desyanti ${ }^{1}$, Febrina Sari ${ }^{2}$, Revaldi Fauzi ${ }^{3}$ \\ 1,2,3, Teknik Informatika, Sekolah Tinggi Teknologi Dumai \\ Jl. Utama Karya - Bukit Batrem II Dumai \\ e-mail :desyanti734@gmail.com¹, febri_ghaniya@yahoo.co.id ${ }^{2}$
}

\begin{abstract}
ABSTRAK
Indonesia merupakan salah satu negara dengan jumlah penduduk terbesar di dunia. Hal ini juga sebanding dengan jumlah angka kecelakaan kerja yang terjadi. Tahun 2019 terdapat 77.295 kasus kecelakaan kerja, artinya ada sekitar 211 kasus kecelakaan kerja yang terjadi setiap harinya, dengan jumlah sebanyak ini perkerja indonesia masih belum dapat memahami bagaimana pentingnya keselamatan dan kesehatan pada saat bekerja. Kurangnya pemahaman tentang K3 menjadi salah satu kendala lainnya, sehingga informasi yang diberikan tidak maksimal dan kurang menarik hal ini membuat karyawan cenderung tidak memperhatikan ketika diberikan informasi, oleh karena itu diperlukan sebuah media untuk memberikan pemahaman tentang pentingnya keselamatan dan kesehatan kerja. Video animasi 2D dibuat secara menarik dan mudah dipahami, dengan menggunakan aplikasi Adobe After Effects CS 6 sehingga memudahkan pengguna dalam mengetahui informasi pentingnya penggunaan Alat Pelindung Diri saat bekerja.
\end{abstract}

Kata Kunci : Animasi 2D, Keselamatan dan Kesehatan Kerja, Alat Pelindung Diri

\begin{abstract}
Indonesia is one of the countries with the largest population in the world. This is also proportional to the number of work accidents that occur. In 2019 there were 77,295 cases of work accidents, meaning that there are around 211 cases of work accidents that occur every day, with this number of Indonesian workers still not able to understand how important safety and health is at work. Lack of understanding of $\mathrm{K} 3$ is another obstacle, so that the information provided is not optimal and less attractive, this makes employees tend not to pay attention when given information, therefore a media is needed to provide an understanding of the importance of occupational safety and health. 2D animated videos are made in an attractive and easy-to-understand way, using the Adobe After Effects CS 6 application, making it easier for users to find information on the importance of using Personal Protective Equipment while working.
\end{abstract}

Keywords: 2D Animation, Occupational Health and Safety, Personal Protective Equipment.

\section{PENDAHULUAN}

Keselamatan dan kesehatan kerja (K3) adalah hal yang sangat penting dan harus diberikan pembinaan kepada seluruh karyawan di sebuah perusahaan, sebagai salah satu upaya pencegahan terjadinya kecelakaan kerja yang dapat menimbulkan cedera fisik, kesehatan hingga kematian. Laboratorium menjadi salah satu departement yang harus di perhatikan dalam permasalahan $\mathrm{K} 3$, unsur kecelakaan pada bagian laboratorium umumnya bersifat tidak terlihat dan menyerang kesehatan dari pekerja laboratorium itu sendiri. Telah banyak terjadi kecelakaan ataupun menderita luka baik yang bersifat luka permanen, luka ringan, maupun gangguan kesehatan dalam yang dapat menyebabkan penyakit kronis maupun akut, serta kerusa kan terhadap fasilitas fasilitas dan peralatan penunjang Praktikum yang sangat mahal harganya (Dinda Nur Syakbania, 2017). Kecelakaan kerja tidak saja menimbulkan korban jiwa maupun kerugian materi bagi pekerja dan pengusaha, tetapi juga dapat mengganggu proses produksi secara menyeluruh, merusak lingkungan yang pada akhirnya akan berdampak pada masyarakat luas.Oleh karena itu K3 seyogyanya melekat pada pelaksanaan praktikum dan penelitian di 
IN F O R M A I I A

Jurnal Informatika, Manajemen dan Komputer, Vol. 13, No. 2, Desember 2021

eISSN : 2580-3042

pISSN : 1979-0694

laboratorium. Pada umumnya kecelakan kerja penyebab utamanya adalah kelalaian atau kecerobohan. Oleh karena itu perlu dilakukan upaya untuk mencegah terjadinya kecelakaan dengan cara membina dan mengembangkan kesadaran (attitudes) akan pentingnya K3 di laboratorium.(Pertiwi \& Yuliyanto, 2015).

PT. Inti Benua Prakasatama (PT. IBP) merupakan perusahaan yang bergerak dalam bidang pengolahan CPO (Crude Palm Oil) dan Pengolahan CPKO (Crude Palm Kernel Oil) menjadi produk turunannya. Departement SHEQ (Safety And Health Environment Quality Officer dalam menyampaikan informasi tentang keselamatan dan kesehatan kerja masih berupa gambar-gambar yang diletakkan di dinding serta Training yang masih menggunakan slide Power Point. Kurangnya pemahaman tentang K3 menjadi salah satu kendala lainnya, sehingga informasi yang diberikan tidak maksimal dan kurang menarik hal ini membuat karyawan cenderung tidak memperhatikan ketika diberikan informasi. Informasi seperti ini dinilai kurang efektif karena dibutuhkan waktu yang lama untuk melakukan training kepada seluruh karyawan yang ada di perusahaan. Kecelakaan kerja di laboratorium sebenarnya dapat dihindari dan diantisipasi jika para praktikan mengetahui dan selalu mengikuti prosedur kerja yang aman di laboratorium, oleh karena itu diperlukan sebuah media untuk memberikan pemahaman tentang pentingnya keselamatan dan kesehatan kerja.

Penggunaan Multimedia Interaktif sudah banyak dipakai dikalangan masyarakat sebagai sarana pemberian informasi yang mudah dipahami dan digunakan. (Pratama, 2020) menggunakan microsoft office power point dalam membuat media pembelajaran keselamatan dan kesehatan kerja, begitu juga penelitian yang dilakukan oleh (Yelisman Zebua, 2020) menggunakan media power point berbasis video untuk membuat media pembelajaran pada mata kuliah keselamatan dan kesehatan kerja, video ini digunakan oleh dosen untuk mengukur kemampuan mahasiswa dalam memahami mata kuliah keselamatan dan kesehatan kerja, hasil yang dicapai dengan adanya media pembelajaran ini $81 \%$ mahasiswa dinyatakan tuntas dan termasuk kategori baik.

\section{METODOLOGI PENELITIAN}

Metode pengembangan sistem yang digunakan adalah Multimedia Development Life Cycle (MDLC), menurut (Riswandari, Yuwita,

\& Setiadi, 2021) metode ini memiliki 6 tahapan yang harus dilalui, yaitu : Concept, Design, Material Collecting, Assembly, Testing dan Distribution. Metode pengembangan sistem dibuat untuk memudahkan pengguna dalam merancang video animasi 2D secara lebih sistematis.

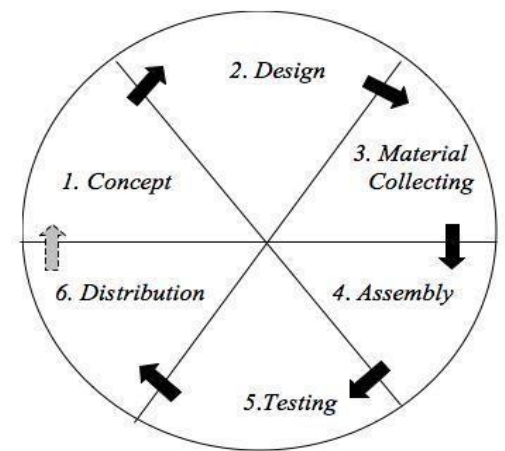

Gambar 1. Ilustrasi Model Multimedia Development Life Cycle (MDLC)

1. Concept

Concept merupakan tahap awal dari metode MDLC, pada tahap ini mulai ditentukan tujuan dari pembuatan video animasi 2D yaitu memberikan informasi keselamatan dan kesehatan kerja (K3) kepada pekerja agar para pekerja/Staff lebih sadar tentang pentingnya implementasi K3 di lingkungan kerja.

2. Design

Aplikasi ini menggunakan Adobe After Effects CS 6 untuk membuat tampilan visual, navigasi serta proses desain media secara lengkap.

3. Material Collecting

Tahap ini merupakan proses untuk pengumpulan data yang dibutuhkan dalam pembuatan video animasi dimulai dengan pengumpulan materi dan bahan - bahan yang berkaitan tentang keselamatan dan kesehatan kerja .

4. Assembly

Setelah semua materi Keselamatan dan Kesehatan Kerja terkumpul, mulai dibuat menjadi sebuah video animasi. Video animasi ini buat berdasarkan flowchart yang sudah dirancang sebelumnya. Berbagai materi serta File- File multimedia tersebut kemudian dirangkai dan disusun sesuai desain yang dibuat pada storyline dan storyboard. 
IN F ORM T I K

Jurnal Informatika, Manajemen dan Komputer, Vol. 13, No. 2, Desember 2021

eISSN : 2580-3042

pISSN : 1979-0694

5. Testing

Setelah proses pembuatan animasi

Keselematan dan kesehatan kerja selesai dibuat, maka perlu diadakan pelaksanaan uji coba. Hal ini dimaksudkan agar media pembelajaran interaktif tersebut sudah sesuai dengan hasil yang diharapkan dan dapat diterapkan pada karyawan PT.Inti Benua Prakatama

6. Distribution

Tahap akhir dari metode MDLC adalah distribution, pada tahap ini media pembelajaran interaktif yang telah memiliki nilai kelayakan baik dan sesuai untuk digunakan sebagai media pembelajaran akan digandakan dan disebarkan kepada pengguna yakni diberikan kepada PT Inti Benua Perkasatama.

\section{HASIL DAN PEMBAHASAN}

Pembuatan video animasi ini mencakup beberapa tahapan salah satunya adalah Praproduksi yaitu pembuatan serta penyusunan konsep dan pengumpulan data yang kemudian di tuangkan kedalam sebuah gambar animasi digital. Dalam penyusunan pembuatan animasi menggunakan metode Story Line untuk menuangkan ide-ide serta gagasan menjadi sebuah alur dan bagan cerita yang sederhana.

\section{a. Storyline}

Storyline merupakan rangkaian cerita yang dibentuk oleh tahapan - tahapan peristiwa yang berbagai macam.(Dion Eko Valentino, Muhamad Jodi Hardiyansyah, 2020) . Video Animasi 2D keselamatan dan kesehatan kerja ini berdurasi 00:04:09:05 menit akan menampilkan opening berupa tampilan dasar-dasar pembuatan Video animasi yang kemudian akan dilanjutkan dengan menampilkan hal-hal yang dapat terjadi akibat dari kecelakaan kerja,jika tidak menggunakan Alat Pelindung Diri (APD) dan beberapa aturan yang sudah ditetapkan oleh perusahaan.Selanjutnya diteruskan dengan menampilkan bentuk dari kecelakaan kerja dan cara mencegah kecelakaan kerja terjadi, dengan beberapa aturan didalamnya.

\section{b. Storyboard}

Storyboard adalah sketsa gambar untuk menggambarkan sekaligus menyampaikan suatu ide cerita kepada orang lain agar lebih mengerti atau memiliki khayalan yang sesuai dengan hasil karya yang dihasilkan. (Yulianjani, Martono,
Apriyani, \& Production, 2019) Storyboard juga merupakan sketsa gambar yang disusun berurutan sesuai dengan naskah (Febriawan, Siregar, \& Cahyadi, 2018). Tujuan dibuat storyboard adalah memberikan gambaran tentang bagaimana urutan-urutan dan animasi yang akan dibuat pada Video Animasi 2D Keselamatan Dan Kesehatan Kerja di laboratorium. Desain Storyboard dari Simulasi Animasi 2D Keselamatan Dan Kesehatan Kerja di laboratorium dapat dilihat pada tabel 1.

Tabel 1. Storyboard Video Animasi Keselamatan dan Kesehatan Kerja

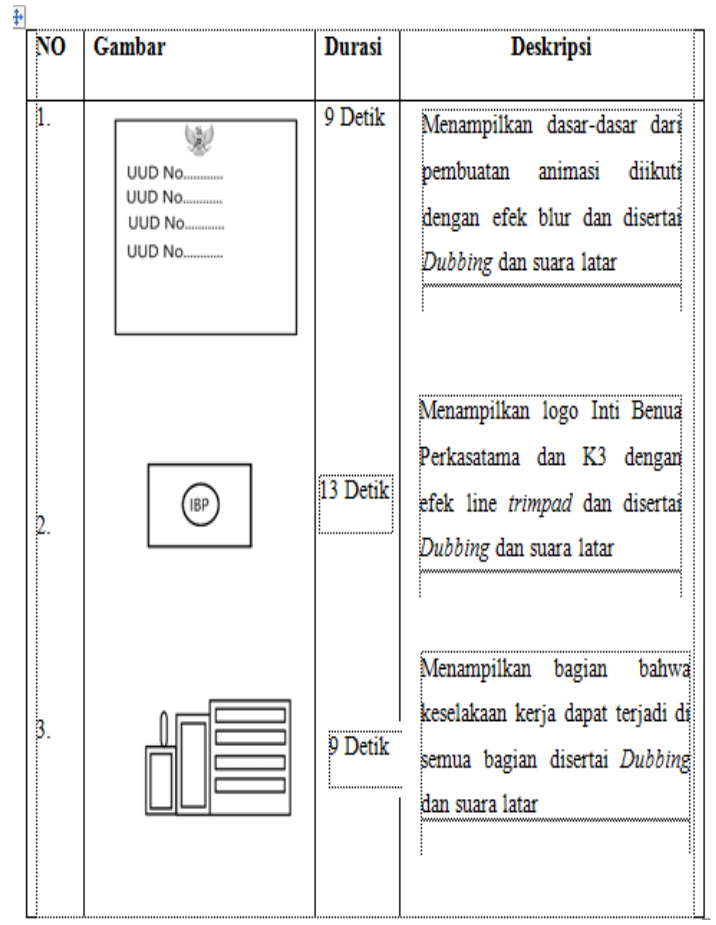

\section{c. Proses Produksi}

Setelah tahap pembuatan konsep dalam Praproduksi di lanjutkan kedalam tahap proses produksi. Pada tahap ini terdiri dari designing, animating, dan Dubbing. Berikut merupakan pembahasan dalam tahap proses produksi.

a. Designing

Video Animasi ini dibuat menggunakan aplikasi Adobe Illustrator CS6. 
INFORM T IKA

Jurnal Informatika, Manajemen dan Komputer, Vol. 13, No. 2, Desember 2021

eISSN : 2580-3042

pISSN : 1979-0694
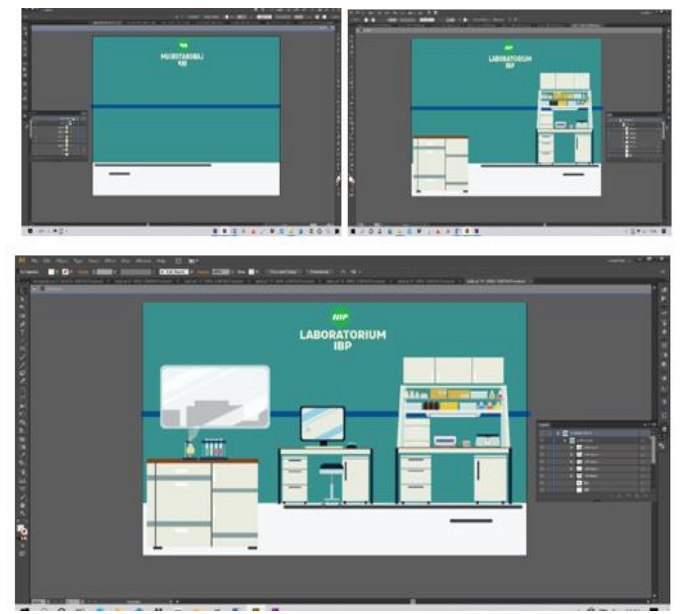

Gambar 2. Pembuatan Objek pada Adobe Illustrator CS6

\section{b. Animating}

Tahap ini menganimasikan bahan grafik yang telah dibuat pada Adobe Illustrator CS6. Pada tahap ini dilakukan dengan Adobe After Effect CS6, dimana bahan grafik digerak satupersatu menggunakan key motion. Bahan grafik yang akan dianimasikan harus dalam layer terpisah dan diberi nama untuk mempermudah proses animasi.

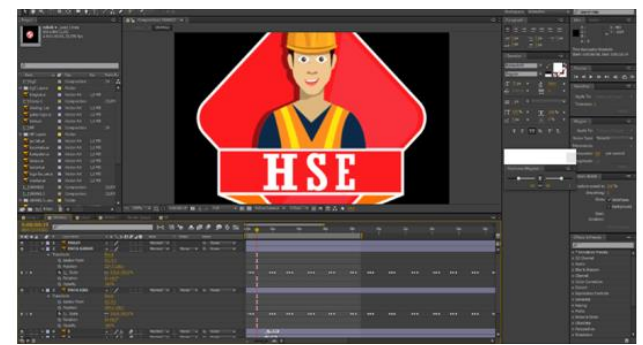

Gambar 3. Fitur Position, Scale, dan Rotation Adobe Affter Effects CS 6

\section{c. Dubbing}

Pengisian suara pada video animasi simulasi ini dilakukan dengan merekam suara kemudian melakukan editing menggunakan Adobe Audition CS6 untuk memperoleh hasil suara yang baik. Sehingga suara dapat diimport pada aplikasi Adobe Premiere Pro CS6 untuk diatur sesuai tampilan animasi.

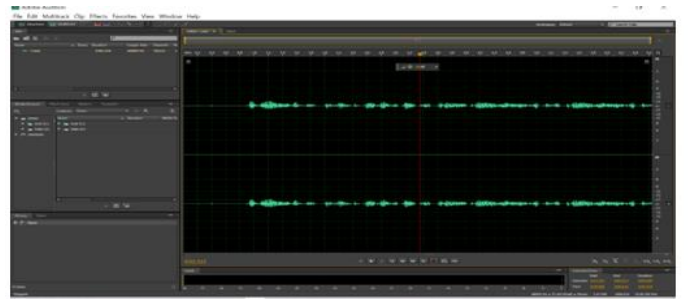

Gambar 4. Proses Rekam Suara pada Adobe Audition CS6

\section{d. Proses Pasca Produksi}

Setelah proses produksi selesai, maka dilanjutkan ke tahap pasca produksi yang tujuannya untuk membangun atau menyampaikan cerita sehingga animasi dan narasi tadi harus diedit dan disusun serta menambahkan soundtrack.

\section{a. Editing}

Proses editing merupakan proses menghubungkan potongan-potongan animasi dan hasil Dubbing narasi pada tahap sebelumnya. Proses ini penulis menggunakan aplikasi Adobe Premiere Pro CS6. Aplikasi ini sebagai sarana combine yang dimana bertujuan untuk menggabungkan video dan suara sebagai langkah terakhir di dalam pembuat video animasi simulasi.

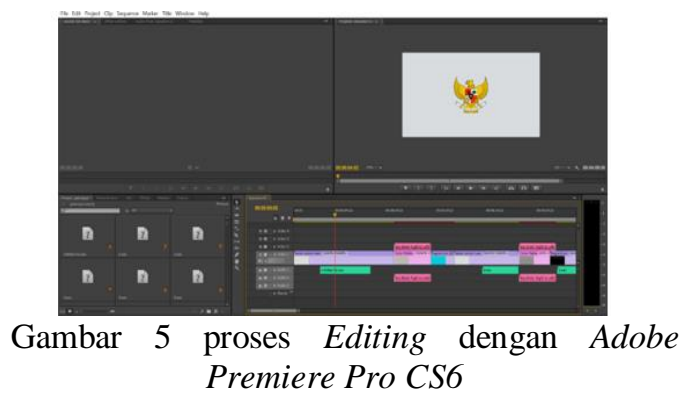

\section{b. Rendering}

Rendering merupakan sebuah tahapan akhir di dalam proses produksi dari video animasi. Proses ini tujuan nya menghasilkan video yang dapat diputar dan disebar dengan mudah dalam format Mp4

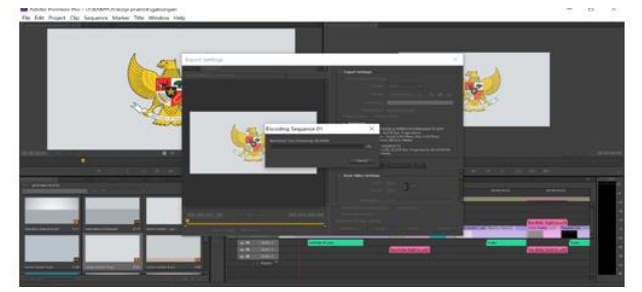

Gambar 6. Proses Rendering Dengan Adobe Premiere Pro CS6 
IN F ORM A I K

Jurnal Informatika, Manajemen dan Komputer, Vol. 13, No. 2, Desember 2021

eISSN : 2580-3042

pISSN : 1979-0694

\section{e. Implementasi}

Hasil akhir dari pembuatan Video Animasi 2D Keselamatan Dan kesehatan Kerja dapat dilihat pada gambar 7 .

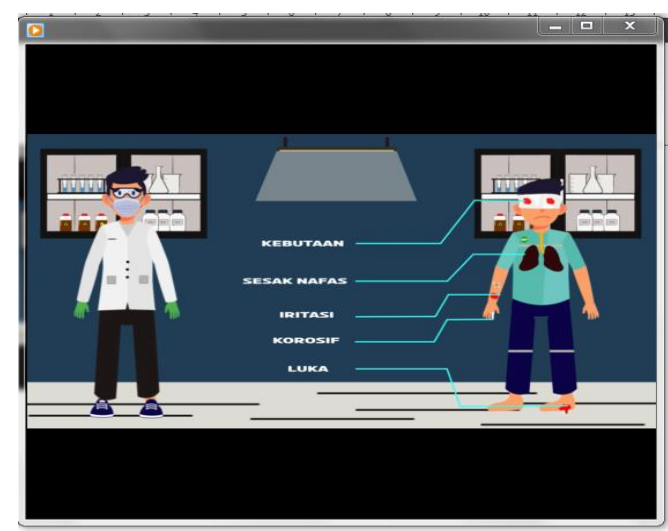

Gambar 7 . Akibat yang ditimbulkan saat pekerja tidak menggunakan APD

\section{KESIMPULAN}

Dibuatnya video animasi 2D keselamatan dan kesehatan kerja di PT Inti Benua Perkasatama agar karyawan lebih menyadari petingnya keselamatan dalam bekerja dan karyawan jadi lebih tau bahaya yang ditimbulkan jika tidak menggunakan Alat Pelindung Diri (APD) saat bekerja. Video yang dihasilkan dapat memberikan informasi secara detail tentang keselamatan dan kesehatan kerja

\section{REFERENSI}

Dinda Nur Syakbania, A. S. W. (2017). HIGEIA JOURNAL OF PUBLIC HEALTH, I(2), 49-57.

Dion Eko Valentino, Muhamad Jodi Hardiyansyah. (2020). Perancangan Video Company Profile Pada Hotel de Java Bandung, 7(1), 1-20.

Febriawan, A. C., Siregar, J., \& Cahyadi, C. (2018). Program Animasi Interaktif Pengenalan Kebudayaan Indonesia, $I V(2)$, 119-124.

Pertiwi, F. C., \& Yuliyanto, E. (2015). ANALISIS PENGETAHUAN KONSEP ( K3 ) LABORATORIUM KIMIA DI MAN 2, (2011), 114-123.

Pratama, R. R. (2020). Pengembangan Media Pembelajaran Interaktif pada Proses Pembelajaran Keselamatan dan Kesehatan
Kerja, 01(01), 53-57.

Riswandari, N., Yuwita, N., \& Setiadi, G. (2021). PENGEMBANGAN E-LEARNING MENGGUNAKAN ADOBE ANIMATE CREATIVE CLOUD DENGAN PENERAPAN METODE MULTIMEDIA DEVELOPMENT LIFE CYCLE, 3, 76-92.

Yelisman Zebua. (2020). MEDIA POWERPOINT BERBASIS VIDEO TERHADAP HASIL BELAJAR MATERI, $3,469-475$.

Yulianjani, A., Martono, A., Apriyani, D., \& Production, P. (2019). APLIKASI MEDIA INTERAKTIF MENGGUNAKAN ANIMASI CERITA RAKYAT UNTUK ANAK USIA DINI ( Studi Kasus Yayasan Bina Insan Kamil Kabupaten Tangerang ), $5(1)$. 